\title{
Estado de Derecho y Transparencia. Un acercamiento desde la historia, el derecho y la ética
}

Rule of law and Transparency. An approach from history, law and ethics

Autores: Javier Rascado Pérez, Raúl Ruiz Canizales

DOl: https://doi.org/10.25058/1794600X.1908 


\title{
ESTADO DE DERECHO Y TRANSPARENCIA. UN ACERCAMIENTO DESDE LA HISTORIA, EL DERECHO Y LA ÉTICA*
}

\author{
Rule of law and Transparency. An approach from \\ history, law and ethics \\ Estado de direito e transparência. Uma abordagem \\ da história, direito e ética
}

Javier Rascado Pérez ${ }^{a}$ javierascado@uaq.mx

Raúl Ruiz Canizales ${ }^{b}$ raul.canizales@uaq.mx

Fecha de recepción: 2 de diciembre de 2020 Fecha de revisión: 12 de diciembre de 2020 Fecha de aceptación: 28 de diciembre de 2020

DOI: https://doi.org/10.25058/1794600X.1908

Para citar este artículo:

Rascado Pérez, J. y Canizales Ruiz, R. (2021). Estado de Derecho y Transparencia. Un acercamiento desde la historia, el derecho y la ética. Revista Misión Jurídica, $14(20), 70-84$.

“...todas las acciones referentes al derecho de otros hombres cuya máxima no puede ser publicada, son injustas." Immanuel Kant

\section{RESUMEN}

El combate a la corrupción se vuelve necesario ante la creciente desconfianza de la sociedad hacia su gobierno. La corrupción ataca la economía y en consecuencia limita el crecimiento de los países y, además, afecta seriamente a la democracia por la pérdida de legitimidad de los representantes. Sin ésta, el Estado constitucional de derecho se aleja de garantizar una mejor calidad de vida de la población. En el presente trabajo, basado en la investigación documental, se concluye que para fortalecer la democracia constitucional, se requiere el reconocimiento del derecho de acceso a la información, y una política pública de la transparencia como antídoto para la corrupción y pilares del fortalecimiento democrático.

*Artículo de reflexión, desarrollado durante la cátedra de Gobernanza y gobernabilidad dentro del programa de la Maestría en Administración Pública de la división de investigación y posgrado de la UAQ.

a. Doctor en derecho y Docente investigador adscrito a la Facultad de Derecho de la Universidad Autónoma de Querétaro, Profesor de Tiempo Libre nivel $V$.

b. Doctor en derecho y Docente investigador adscrito a la Facultad de Derecho de la Universidad Autónoma de Querétaro, Profesor de Tiempo Completo nivel VII. 


\section{PALABRAS CLAVE:}

Corrupción; transparencia; legalidad; ética; democracia.

\begin{abstract}
:
The fight against corruption becomes necessary facing society's growing distrust in its government. Corruption undermines economy and, as a consequence, limits the growth of countries and seriously affects democracy due to the loss of legitimacy of representatives. Without it, the constitutional Rule of Law can not guarantee a better quality of life for its population. This research, which is based on documentary investigation, concludes that for strengthening constitutional democracy is necessary to aknowledge the right of access to information and a public policy of transparency as an antidote against corruption and as a pillar for democratic consolidation.
\end{abstract}

\section{KEY WORDS}

Corruption; transparency; legality; ethics; democracy.

\section{RESUMO}

0 combate à corrupção torna-se necessário devido à crescente desconfiança da sociedade em relação ao seu governo. A corrupção ataca a economia e, consequentemente, limita o crescimento dos países e, além disso, afeta gravemente a democracia pela perda de legitimidade dos representantes. Sem ela, o Estado de Direito constitucional está longe de garantir uma melhor qualidade de vida à população. No presente trabalho, com base na pesquisa documental, conclui-se que para o fortalecimento da democracia constitucional é necessário o reconhecimento do direito de acesso à informação e uma política pública de transparência como antídoto à corrupção e pilares do fortalecimento democrático.

\section{PALAVRAS-CHAVES}

Corrupção; transparência; legalidade; ética; democracia.

\section{INTRODUCCIÓN}

La pregunta central, en torno a la cual gira la presente disertación, es: ¿bajo qué condiciones el derecho humano de acceso a la información pública puede operar como una prerrogativa que rescate el ideal del poder del pueblo y de qué forma la ética, como valor transversal en todos los ámbitos y niveles, puede operarse como una herramienta que nos garantice el logro, al fin, de los ideales que han edificado este modelo de Estado, cuyo fin máximo es lograr la dignidad de las personas?

Para contextualizar el objeto de estudio es necesario recordar que la Edad Media, se caracterizó por un ejercicio absolutista del poder y la inexistencia de derechos para las personas; fue el caldo de cultivo de las ideas liberales que, enmarcadas en el iluminismo, finalmente se ven materializadas en los movimientos libertarios, la Independencia de los Estados Unidos y la Revolución Francesa, dando por concluido un oscuro periodo de occidente. A partir de ahí, los movimientos a favor de mayores libertades civiles y políticas fueron incluyendo en su agenda nuevas exigencias que se tradujeron, poco a poco, en la búsqueda de esquemas que garantizaran una relación más equilibrada entre sociedad y Estado.

El surgimiento del Estado Moderno, cuya existencia se justifica desde la soberanía popular, se presenta como el anhelo liberal que reconoce derechos a las personas y limita el poder. Es el fin de los privilegios y las desigualdades, el sometimiento de todos al mandato de la ley $y$, el reconocimiento y respeto de las libertades. Surge entonces, el Estado de Derecho. Desde éste, y basado en el principio de legalidad, se institucionaliza el ejercicio del poder público y se construye un sistema de reconocimiento y validez en el que, solo serán válidos aquellos actos cuyo reflejo se reconoce desde la Constitución.

Como consecuencia de lo anterior, el Estado de Derecho surge como el nuevo paradigma al que se suman aquellos países que, sacudiéndose el poder absolutista, desean inscribirse y ser reconocidos en el nuevo contexto internacional como modelos democráticos. Aunque con variaciones en el tiempo, es este modelo el nuevo paradigma que será adoptado por prácticamente todo occidente. Un modelo que, se basa en la soberanía popular como origen del poder, en la representación como delegación de la voluntad para su ejercicio, y la división de funciones en la práctica del poder como límite. Todo ello, desde el sometimiento de todo el sistema al mandato de la ley. 
La desigualdad que el nuevo modelo de producción económica generó, así como la burocratización de los modelos estaduales y los permanentes conflictos bélicos generados en diversas latitudes, pusieron de manifiesto las debilidades del modelo liberal que exigía un Estado mínimo interventor.

A la culminación de la Segunda Guerra Mundial se hizo patente la necesidad de ajustar el modelo y volverlo más sensible y atento a las crecientes necesidades y exigencias de una comunidad. Aunado, a la globalización de los modelos económicos y el desarrollo de los medios de comunicación, evidenciaron el agotamiento del modelo.

La democracia cuantitativa se torna insuficiente, ya que se agota en una participación limitada al ejercicio del voto y no atiende a la pluralidad de una comunidad. Se tiene que transitar hacia una democracia que garantice la calidad de vida de la población y otorgue mayor protección de los derechos de las personas. Derechos que a la vez se extienden y universalizan. Se transita hacia un Estado Constitucional de derecho y en consecuencia, hacia la democracia constitucional como sistema político y de vida.

Pero en la actualidad son aún muchos los obstáculos para la maximización de los derechos y la consolidación del modelo democrático. Entre ellos la corrupción, que, aunque en diferentes magnitudes y dimensiones, parece ser la constante en todos los modelos económicos y sistemas de gobierno. No hace diferencia entre países ricos o pobres, democracias consolidadas o no. Se presenta en todos los ámbitos. Se constituye pues, en un cáncer de la democracia.

Un país invadido por la corrupción no solo representa pérdidas económicas, sino que además debilita el sistema institucional por la deslegitimación del ejercicio del poder público. Y como consecuencia, impide que se logren los fines del Estado: la satisfacción de las necesidades y la mejoría en la calidad de vida de una población. Por ello, resulta siempre pertinente toda reflexión crítica y autocrítica que abone a la presente discusión; más aún cuando, a pesar de los tiempos de avances normativos y políticos en materia de transparencia, las pautas éticas de muchos actores del espacio público parecen visibilizar - a la par- el océano de carencias en la materia, lo que se erige en una amenaza constante al propio Estado de Derecho. México es una prueba palpable de esta situación, y por ello, se ha convertido en bandera política de todo el sistema mexicano, tanto en el ámbito público como privado. Se vuelve urgente combatirla para lograr el fortalecimiento institucional del país y que el Estado pueda lograr sus fines. En este sentido, y en pleno Estado Constitucional, se debe echar mano a los derechos y herramientas existentes para combatirlo y erradicarlo.

Es en virtud de lo anterior que el objetivo del presente escrito consiste en realizar una descripción de la evolución y el grado de madurez que ha adquirido hasta nuestros días el binomio Estado de Derecho-transparencia, pero a través el crisol de la historia, del derecho, y por supuesto, desde la ética. Desde la dimensión de la filosofía moral, el propósito fundamental es intentar dar respuesta a la pregunta sobre por qué resulta necesario abordar el tema de acceso a la información desde un punto de vista moral, así como a la interrogante sobre cómo asociamos la moral y transparencia. La hipótesis encierra la idea de que el principio de publicidad (como hilo conductor al momento de tejer la respuesta y visto como un derecho humano) da contenido al derecho de acceso a la información pública (DAIP), así como a las discusiones sobre las políticas de transparencia. A su vez el principio de publicidad (de igual manera visto como un derecho humano) constituye la vía natural que permite despejar la discusión acerca de la relación que históricamente ha habido entre el binomio derecho-moral en el que los ciudadanos a su vez son vistos como agentes morales.

\section{ESTADO DE DERECHO: CONCEPTO Y EVOLUCIÓN}

Al principio fue la rivalidad entre los distintos ostentadores del poder de mando: señores feudales, reyes, emperadores y papas. Esta rivalidad toma su punto más álgido en la organización política de la Edad Media. Es en ese contexto de confrontación en el que se produce dos efectos que, por lo menos histórica y jurídicamente, resultan de gran importancia: por un lado, la consolidación del poder del Estado, gracias a la doctrina de la soberanía; y por otro, la instauración del absolutismo monárquico, como una expresión gradual previo al surgimiento de lo que se denominó después como 'Estado burgués 
de Derecho'. Y es también en esta etapa de transición en la que aquellas formas o esquemas sociales de producción desembocan en un sistema económico que desde entonces se ha llamado capitalismo. Ambas figuras -Estado burgués y capitalismo- son caras de la misma moneda, se dan la mano para configurar una nueva forma de organización social, política, jurídica y económica. De hecho, la organización política característica de este sistema económico, el capitalismo, es el originalmente denominado 'Estado burgués de derecho'. La expresión en sí obedece, en una primera instancia, al hecho de que la clase social que impulsó su aparición fue la burguesía, cuyo hito apoteótico se atestigua con la Revolución Francesa; en segunda instancia, porque una de sus características esenciales reside en que la convivencia social está regida por un orden jurídico 'estable', sometido al Estado mismo. La fórmula se expresa de la siguiente manera: mientras que en el Estado absolutista (típico de la etapa superior del feudalismo) las leyes las dictaba el monarca $y$, por tanto, el derecho estaba subordinado a la voluntad y albedrío de quien encarnara el poder; en cambio con el Estado burgués de derecho ese mismo poder se encuentra sometido al Derecho, cuya expresión se da en relación a un conjunto de normas fundamentales que permiten desprender el resto del orden jurídico. Esa norma fundamental es la constitución, y tanto a la producción literaria como a los diversos tipos de constituciones (expresiones constitucionales) se le ha denominado constitucionalismo. En nuestros días la expresión constitucionalismo (usada con el significado de doctrina de la delimitación jurídica del poder) tiene como sinónimo los conceptos de separación de poderes, rule of law, legalidad y Estado de Derecho (Barberis, 2008, pp. 125-150).

No obstante lo descrito y aunque es de uso cotidiano y empleado en distintos modelos estaduales, parece ser que no existe unicidad en cuanto al origen y significado del concepto 'Estado de Derecho', entendido éste como límite al ejercicio del poder, pues en estricto sentido encontramos referentes desde el pensamiento filosófico griego y romano. Más allá de las narrativas históricas, para algunos se desprende del imperativo categórico de Kant. Otros más lo identifican en los antecedentes del constitucionalismo inglés. Lo cierto es que constituye un concepto occidental que, por lo menos en las dos familias jurídicas predominantes en Occidente (Romano-Germánica y Common Law-), se identifica su existencia.
Como apunta Stolleis, "Visto con perspectiva histórica, se trata más bien de una pieza del pensamiento europeo, que también comprende Norteamérica, formada entre 1750 y 1850 , y que desde entonces se ha impuesto progresivamente, aunque con quiebras catastróficas en el siglo XX" (2018, p. 100). Evidentemente con diferencias sustanciales, ya que cada Estado es resultado de su propia historia, de los movimientos que le dieron identidad y de sus muy particulares conformaciones internas.

Existe acuerdo en que, en un primer momento, es en el Rechtsstaat donde se clarifica esta concepción, toda vez que este concepto se origina en la obra de Robert Von Mohl, el cual es posteriormente desarrollado por otros pensadores (Márquez en: Cienfuegos, 2008, p. 212). Encuentra su origen en el sistema jurídicopolítico alemán, pero con impacto en todo el pensamiento occidental. Ahora bien, en estricto sentido, el concepto Rechtsstaat es la expresión débil de uno de los tres significados de lo que se conoce como Estado de Derecho y, como se explicó, a su vez, ésta última es uno de los sinónimos de la expresión constitucionalismo. En este sentido, mientras que Rechtsstaat, como uno de los sinónimos de Estado de derecho, señala un Estado sujeto genéricamente al derecho (de ahí su consideración como expresión débil), los otros dos sinónimos hacen alusión a un proceso de consolidación gradual del mismo: el sentido fuerte de Estado (de derecho) legislativo sujeto específicamente a la ley; y el sentido fortísimo de Estado (de derecho) constitucional, sujeto todavía de manera más específica a la constitución (Barberis, p. 150). Así pues, el término Estado de Derecho se ha venido utilizando para vincular el Estado y el derecho, no solo en términos de legalidad, sino además para generar certidumbre e impedir un ejercicio absolutista del poder. El pensamiento de Mohl puede sintetizarse en la visión de un ordenamiento de la vida del pueblo en la que cada ciudadano es sostenido y ayudado en el ejercicio de su libertad (Revenga, 2019, p. 36). Se concibe el derecho al servicio de la sociedad. El Estado de derecho gira en torno al principio de legalidad, a la sumisión a la ley de todo el aparato administrativo, la separación de poderes y la existencia de derechos ciudadanos que se ejercen frente al Estado.

Miaille considera que, a pesar de haber sido desdeñada, la visión de Hegel es la que permea 
en el pensamiento eurocentrista. Una visión que sostiene es idealista y optimista, en la que "El Estado afirma que está situado por encima de los intereses privados, ya que representa el interés general; detenta el monopolio de la fuerza, ya que no pertenece a nadie en particular y que, en última instancia, la fuerza debe siempre estar del lado de la ley..." (1985, p. 157).

Se desprende de la idea del Estado de Derecho, la necesidad de constreñir todo el actuar social, así como el ejercicio del poder, a un marco de legalidad en donde se construye un sistema de reconocimiento y de validez para todos los actos. Con ello se materializan los ideales del iluminismo: el reconocimiento de los derechos de las personas como límite al ejercicio del poder.

En su formulación original, en el Estado de derecho está lejana la intención meramente democrática, se pretende en realidad legalizar la dominación. Por ello, partiendo desde su origen, debe atenderse a su evolución para comprender su sentido en la actualidad.

Se puede dar por evidente que todo Estado es de derecho, ya que no existe alguno que no tenga un conjunto de normas jurídicas establecidas, así como un sistema de reconocimiento y validez. Existe en toda conformación estadual un discurso dominante que, sin importar su legitimidad o aceptación, construye el discurso que es reconocido como válido y es imperativo para todo el conjunto social. Es posible hablar o no de democracia, que es el ideal que siguen los Estados en la actualidad, pero no se puede dudar de la existencia de un Estado en que impere un discurso dominante y éste se institucionaliza.

Siguiendo la línea evolutiva del concepto, se transita de un mero sometimiento al mandato de la ley, hasta una postura más elaborada que crea todo un sistema de reconocimiento y validez, que además apuesta por un modelo democrático. Así entonces, según lo explica Orozco, “...como resultado de la influencia del constitucionalismo liberal burgués, la expresión 'Estado de derecho' adquirió una connotación técnica y se identificó con un ideal político específico, y se utiliza para designar cierto tipo de Estado que se estimaba satisfacía las exigencias de la democracia y de la seguridad jurídica" (2007 p. 1564).
Siguiendo a Orozco, nos explica que este calificativo era entonces reservado a aquellos sistemas que contuvieran las instituciones del pensamiento liberal de la época, tales como la distribución y control del ejercicio del poder; supremacía constitucional; sometimiento a la ley (principio de legalidad); órgano legislativo y judicial; derechos fundamentales y garantías; racionalización del poder, en resumen, todo el órgano estatal sujeto a la ley (p. 1565). Para Zagrebelsky el Estado de derecho indica un valor, y éste "...es la eliminación de la arbitrariedad en el ámbito de la actividad estatal que afecta a los ciudadanos" (2009 p. 21).

En sus albores el Estado de derecho se relaciona con el apego irrestricto de la ley y la eliminación de la arbitrariedad. En el siglo XIX el Estado liberal de derecho apunta a un fortalecimiento de la sociedad ante el ejercicio del poder público, protección de los ciudadanos ante la arbitrariedad administrativa. Con lo que se da un giro en el siglo XX al Estado constitucional. Se diluye esa separación entre gobernantes y gobernados que apostaba a la legalidad primigenia. Recordemos que “...es característico del Estado liberal de derecho el modo en que se establecía la línea de separación entre Estados y ciudadanos" (Orozco, 2007, p. 28).

Pero el Estado, como conformación social, ha evolucionado a la par que las ideas y los movimientos sociales que lo exigen. Si bien la primera urgencia que tenían los nuevos Estados surgidos de los movimientos libertarios (independencia de los Estados Unidos y Revolución Francesa), era limitar el ejercicio absolutista del poder, como respuesta urgente al absolutismo previo y también ante la consolidación de la nueva forma de organización estadual, fueron germinando los ideales del liberalismo político y se hizo cada vez mayor la necesidad de la protección de los derechos humanos.

El Estado ya no como mero observador y reactivo ante las violaciones del pacto establecido, sino con una cada vez mayor participación activa para mejorar la calidad de vida de la población. Se exige del Estado un rol activo en el que no slo se convierta en vigilante, sino además promotor de una mejor calidad de vida. Esta necesidad redefinió al Estado de derecho, ya no únicamente como origen y control de la legalidad, sino además 
como promotor y defensor de los derechos humanos. Esta evolución "...se traduce ante todo en la centralidad de la ley, máxima expresión de la soberanía del Estado, y por eso mismo máxima fuente del derecho, y a la vez, como consecuencia, también modo principal y privilegiado de garantía de los derechos" (Fioravanti, 2016, p. 131).

Otro concepto del Estado que atiende una nueva realidad, que si bien se sustenta en su concepción original, ahora se reescribe para un nuevo modelo del Estado. Bajo

El análisis de la evolución del Estado nos permite concluir que el Estado de derecho es un modelo organizativo que se ha desarrollado en respuesta a ciertas demandas, necesidades, intereses y exigencias de carácter social, económico, político y cultural, y que una doble vía pretende lograr una mayor participación de los individuos $\mathrm{y}$, al mismo tiempo, una mayor responsabilidad de los poderes públicos (Mejía, 2018, p. 28).

Un elemento central en esta transformación lo encontramos en los derechos humanos. Aunque no con mucha claridad desde sus orígenes, el Estado de derecho contempla su existencia; éstos en su inicio se vislumbran como límite al ejercicio del poder, no siendo su principal finalidad otorgar una mayor protección y calidad de vida a las personas. Baste recordar que “...la doctrina europeo-continental del Estado de derecho no contempla, sino que rechaza, la presencia de un catálogo de derechos fundamentales, a imagen de la Declaración de derechos de 1789" (Fioravanti, p. 107), fenómeno que se repitió en los nacientes Estados modernos ${ }^{1}$.

Evolutivamente, desde finales del siglo XVIII y durante todo el siglo XIX, el papel de los derechos fundamentales se fue posicionando en los textos constitucionales y en el naciente discurso institucional, pero de forma tímida en cuanto a representar una verdadera garantía de estos para la población. Los primeros derechos fundamentales eran limitados y con una gran exclusión en cuanto al reconocimiento y garantía. Así, las "democracias" de la primera mitad del siglo $\mathrm{XX}$ en donde se ejercía el poder de las mayorías,

1. La constitución de Filadelfia no contemplaba derechos, surgen posteriormente en las enmiendas; y en el caso mexicano, la constitución de 1824 tampoco contemplaba su existencia. se convirtieron en una amenaza a los derechos de las minorías. Se genera un modelo inequitativo en donde se deja en total desamparado a los grupos vulnerables.

Posterior a la SGM, principalmente en Europa, se replantea la pasividad del Estado ante las crecientes diferencias y la desigualdad social. Se anticipa la necesaria participación del Estado lejos de esa inicial pretensión del liberalismo de un mínimo Estado interventor. Se requiere el equilibrio social por medio de la intervención del Estado, entendiendo que su finalidad es garantizar el valor máximo de las personas: la dignidad. Por ello, se transita a un Estado activo, sensible y dinámico, que no solo está atento a las necesidades de la sociedad, sino que además enfoca sus esfuerzos y recursos, además garantiza la calidad de vida. Es éste al surgimiento del Estado Constitucional de derecho.

Si bien el Estado Constitucional para algunos representa un cambio paradigmático en oposición al Estado legislativo, es oportuno seguir el planteamiento que sostiene Rodolfo Vázquez, en el cual: al hablar de paradigma tenemos que remitirnos a Kuhn que es quien acuña el concepto, $\mathrm{y}$ en él vemos entonces que no hay cambio en el paradigma del Estado de derecho, sino una experiencia acumulativa que lo redefine (2015, pp. XVI-XVII).

Entonces, nos aunamos a la propuesta de Ferrajoli para quien "El constitucionalismo es un perfeccionamiento del positivismo jurídico $y$ el estado constitucional de derecho una prolongación del estado legislativo de derecho" (2011 p. 469). Evoluciona el concepto. Ahora el Estado se enfoca ya no en el límite al ejercicio del poder, sino a la maximización de los derechos humanos. Son éstos el medio por el cual se garantiza la dignidad de las personas y con ello mejorar su calidad de vida. Por tanto, ahora el objetivo del Estado es no solo crear el catálogo de derechos, sino además crear los mecanismos, procedimientos e instituciones para garantizar su realización.

El Estado Constitucional de derecho consiste en la inclusión de valores y principios en el texto constitucional, por el cumplimiento del principio de legalidad y por establecer los mecanismos que materialicen el ejercicio de los derechos humanos. 
Pero también se trata, como se describió, de una nueva expresión del constitucionalismo occidental, de una nueva faceta en su historia y que tiene como punto de partida sobre todo el siglo XVIII, si se quiere; pero se trata también de una nueva relación del orden político y del orden constitucional como una etapa de superación del arcaico Estado de Derecho. Hay que tener bien presente que a partir de la segunda posguerra inicia esta nueva relación, en efecto,

Según una afirmación ampliamente difundida en el discurso jurídico, el carácter normativo de las Constituciones contemporáneas residiría en la existencia de un control jurisdiccional de las mismas, capaz de imponer su contenido, llegado el caso, a los propios poderes políticos encargados de desarrollarla. De esta constatación se desprendería la posibilidad de eventuales conflictos entre los órganos jurisdiccionales encargados de custodiar el cumplimiento de la Constitución y los órganos políticos encargados de respetar o desarrollar su contenido o, dicho en términos más genéricos, entre derecho y política (Pisarello, en Carbonell, et al, 2004, pp. 17-21, 113).

La nueva cuestión social o esas nuevas realidades sociales y económicas, entonces, vendrían a exigir sistemas jurídicos más efectivos de control político, pero también de mayor control y vigilancia hacia los derechos fundamentales. Este es uno de los elementos en el que mayormente se enfocaría la doctrina constitucional de la posguerra y en el que se encuentra toda la discursividad del trinomio derechos sociales, igualdad y equidad, vistos éstos dos últimos también como principios morales de justicia, además de simples principios jurídicos.

\section{DEMOCRACIA CONSTITUCIONAL}

La democracia como vocablo de uso cotidiano en no pocas ocasiones se descontextualiza o se pierde en el ideario de la superioridad moral a la que un sistema aspira. Con una evolución que ha acompañado al mundo occidental, la democracia ha sido abordada desde distintos ángulos y servido para muy distintos fines, pero sin duda se convirtió en el modelo aspiracional de las mejores formas de gobierno.

Por ello, el Estado moderno adopta la democracia como la forma de gobierno a la que se habrían de sumar todos los nacientes Estados alejándose de los absolutismos que durante siglos había imperado en Europa y sus colonias.

La democracia es el modelo exigible a todo Estado que desee ser aceptado en el discurso occidental. En sus albores, por democracia se entiende el sistema que deposita en la ciudadanía la decisión de quienes habría de detentar el poder político. En una definición mínima, para Bobbio la democracia “...es caracterizada por un conjunto de reglas (primarias fundamentales) que establecen quién está autorizado para tomar las decisiones colectiva y bajo qué procedimientos" (1996, p. 25).

Estos primeros modelos democráticos, aunque aplaudibles. eran limitados en muchos aspectos, ya que prácticamente constreñían la participación ciudadana a la emisión del voto para la elección de autoridades, excluyéndolo de la participación cotidiana y permanente en la toma de decisiones. Además, de otras limitantes, como la imposibilidad de las mujeres para votar.

Como se sostiene, aunque limitado, este modelo se acerca al ideal de gobierno que justifica el origen del poder desde la población. Ésta es una democracia de mayorías, ya que la forma de tomar la decisión atiende a quien más votos obtenga, modelo que en sociedades homogéneas cuyas exigencias eran en realidad pocas, resultó una opción viable que durante, aproximadamente un siglo fue una respuesta satisfactoria y legitimadora del ejercicio del poder público.

La transformación de estas sociedades homogéneas a estructuras más plurales apuntó a la necesidad de nuevos modelos para atender las nuevas exigencias. Derivados de la globalización económica y el desarrollo de los medios de comunicación, aunado a la movilización, tenemos ahora conformaciones sociales heterogéneas que representan mayor exigencia y complejidad para el Estado. Lo que anteriormente se resolvía por mayorías, es ahora insuficiente con una sociedad fragmentada que no logra mayorías absolutas, sino que se conforma de múltiples minorías que exigen una representación en los espacios de toma decisión. Necesitan que su voz sea escuchada y sus demandas atendidas. A partir de esta nueva realidad se comenzó a transitar de democracias cuantitativas a cualitativas, en las que no solo abren los mecanismos de participación clásica 
(votaciones para la elección de representantes populares), sino además se garantizan mayores vías de participación. El nuevo contexto social exige gobiernos abiertos a la permanente participación. Hoy, la corresponsabilidad es una nueva exigencia en el actuar público y por ello se requieren mecanismos de comunicación y participación continuos y amplios. A este contexto se asocia la idea de democracia deliberativa, la cual, de acuerdo con J. Bessette, constituye la última expresión de la ética angloamericana y surge como una continuación de, y una reacción a, la teoría (democracia) procedimental. Bajo el espectro semántico de la democracia deliberativa, los ciudadanos son concebidos como individuos cuyas preferencias se forman sólo a través de la discusión o deliberación; según se explica, en este tipo de democracia los individuos no saben realmente lo que quieren, sino que ello se esclarece a partir del momento en que lo confrontan con lo demás y a partir del momento en que se informan sobre las propuestas y alternativas (en Barberis, 2018, p. 76).

A mediados del siglo pasado se abandonó en Europa el modelo liberal del Estado mínimo interventor. Se comprendió que el Estado debe tener un papel menos pasivo para garantizar las condiciones mínimas de satisfacción de necesidades de la población. Evitar la desigualdad social y apostar por el beneficio colectivo de la sociedad. Y sobre todo, redimensionando el papel de los derechos humanos como fin primero y último del Estado. Solo a través de garantizar éstos se aspira a una mejor la calidad de vida de la población, "Solo la democracia puede brindar dignidad" (Dworkin, 2014, p. 460). Se observa que los Estados con mayor desarrollo democrático, lo han basado en un respeto irrestricto a los derechos humanos.

El nuevo modelo democrático pasa necesariamente por la transición al Estado Constitucional de derecho, es decir, la importancia que en el nuevo modelo estadual ahora juegan los derechos humanos. "En este sentido los derechos fundamentales no son más sólo la garantía de la libertad privada con en el Estado de derecho, sino son también el fundamento de la creación del espacio público de la democracia" (Gozzi, en Espinoza, p. 285).

La democracia constitucional exige más que simple procedimientos para designar a quien detente el poder político y ejercer su control, sino que aspira a materializar los fines del Estado tales como la justicia social, la igualdad o incluso la felicidad. Es un régimen en donde se establecen reglas para que la toma de decisiones colectivas sea incluyente, además de la existencia de valores $\mathrm{y}$ principios. Es "...el régimen de la igualdad política y de la libertad política" (Bovero, en Ferrajoli, p. 68).

La calidad en la democracia es la exigencia contemporánea. Para medir su calidad no sólo se deben respetar los derechos políticos y las libertades civiles, sino que además se requieren gobiernos sensibles que escuchen y atiendan las necesidades de la comunidad. Para ello, se deben abrir mecanismo de participación constante y permanente en que la población sea corresponsable con el actuar público.

Por último, la rendición de cuentas como elemento del control del poder político, que además abona a la legitimidad de quien lo detenta y ejerce. Esa visión patrimonialista que se tenía del Estado es contraria a la nueva realidad del ejercicio público. Solo bajo el escrutinio permanente y la publicidad se garantiza un Estado democrático pleno. Todo lo anterior, dentro de un marco legal e institucional robusto que permita la realización de una democracia cualitativa.

La Corte Interamericana de Derechos Humanos (CIDH), reiterando que el principio de legalidad, las instituciones democráticas y el Estado de Derecho son inseparables, indicó que en cualquier sociedad democrática los derechos y libertades de las personas, así como sus garantías y el propio Estado de Derecho, se definen y adquieren sentido en función de los otros ${ }^{2}$.

Con base en las obligaciones internacionales que prácticamente la totalidad de los Estados han adquirido en relación con la protección de los derechos humanos, éstos se han convertido en limitantes del actuar gubernamental, teniendo que obedecer a los lineamientos acordados en los tratados internacionales que los consagran. Por ello, incluyendo en la democracia un componente de cumplimiento de las obligaciones internacionales se apunta hacia una garantía cabal de dichos derechos por parte de los Estados

2. Corte Interamericana de Derechos Humanos. Opinión consultiva OC-9/87 del 6 de octubre de 1987. 
que conforman la comunidad internacional teniendo presente al ser humano como centro de su actividad gubernamental.

\section{CORRUPCIÓN: CÁNCER DE LA DEMOCRACIA}

La corrupción es un fenómeno que se extiende en todas latitudes y se encuentra lejos de ser exclusivo de los países cuyas democracias no se han consolidado o de aquellos en que ni siquiera se visibiliza su existencia. Existe en todos los ámbitos de la sociedad, incluso en las democracias consolidadas. La democracia no es aquel sistema en el que se dejan de cometer delitos o conductas ilegales, sino aquella en la que se institucionalizan los mecanismos para que bajo el marco de legalidad se sancione a quien incurra en la comisión de este tipo de actos.

La corrupción necesita para existir un sistema normativo y social, ya que es alterando sus reglas como se presenta un acto de corrupción, cuando por obtener un beneficio se solicita a alguien que haga o deje hacer algo que las propias reglas establecen. La forma de responder ante este acto, es lo que fortalece o debilita el sistema institucional, más no el acto de corrupción en sí.

Como se dijo, la corrupción existe en todos los países, la diferencia se establece en el grado en que ésta permea. En algunos se vive de manera abstracta cuando se descubren escándalos en altas esferas del gobierno; en otros, se manifiesta de manera cotidiana y es sufrida por toda la población, afectando negativamente su calidad de vida. Además, impacta directamente las estructuras del Estado con el consecuente debilitamiento institucional, minando a la vez la confianza de la población y la consecuente deslegitimación de las autoridades. En ambos casos se debilita el modelo democrático.

La corrupción afecta al estado de derecho y a la democracia constitucional. Atenta contra el principio de legalidad, ya que los actores tanto públicos como sociales se encuentran en una posición cuya actuación fuera de los límites de la ley les permite lograr objetivos de carácter privado. Asimismo, este fenómeno desvirtúa el sentido sustancial de la democracia. La corrupción trastoca el normal funcionamiento del Estado, alterando la prestación de los servicios públicos cuya finalidad es garantizar que se materialicen los derechos humanos, generando inequidad y desigualdad de la población. Abordar este concepto no es tarea sencilla, ya que existe falta de unanimidad en cuanto a su definición. Por ello la importancia de generar un consenso que dé certidumbre en cuanto a la identificación de este fenómeno y los mecanismos para combatirlo. En efecto, "La palabra corromper proviene del latín corrumpere y supone alterar, trastocar la forma de alguna cosa" (Reyes, 2012, p 8). Pero, como él mismo sostiene, es la segunda acepción la más interesante, corromper es "Echar a perder, depravar, dañar, pudrir..." (8).

En el ámbito del derecho internacional, la Convención Interamericana Contra la Corrupción fue el primer convenio internacional en esta materia. Para la Corte Interamericana de Derechos Humanos es fundamental el combate a la corrupción, ya que es necesario en el fortalecimiento de los derechos humanos $y$ en consecuencia en el fortalecimiento de las democracias. En el mismo sentido Mariela Morales señala que los “...tratados y los procedimientos especiales de las Naciones Unidas han observado que cuando la corrupción es extendida, los Estados no pueden cumplir con las obligaciones en materia de derechos humanos" (2018, p. 343).

Por lo tanto, si la finalidad del Estado Constitucional de derecho es mejorar la calidad de vida de la población, la existencia de la corrupción es un índice negativo y su ineficaz combate impide la realización del mismo. Ante ello, la urgencia de generar mecanismos y herramientas para el combate y erradicación de la misma.

\section{DERECHO DE ACCESO A LA INFORMACIÓN PÚBLICA Y TRANSPARENCIA EN EL COMBATE A LA CORRUPCIÓN}

Inicialmente se describe la forma como se relaciona la ética y el acceso a la información (Cruz, 2015, pp. 6-8). Las preguntas a responder son: ¿Por qué es necesario abordar el tema de acceso a la información desde un punto de vista moral? ¿Cómo asociamos moral y transparencia?, y ¿De qué manera es posible entrelazar el enfoque de la ética aplicada con lo relativo al acceso a la información? El hilo argumentativo para responder dichos interrogantes se plantea según los siguientes términos:

La clave está, en primer lugar, en el principio de publicidad. ¿Por qué? Porque es el principio que funda el derecho de acceso a la información pública y las discusiones sobre las políticas 
de transparencia, y porque constituye la vía que permite resolver la vieja discusión sobre la relación entre el derecho con el punto de vista moral. Una relación que, más allá de las repercusiones teóricas que ello supondría (Prieto, s. f., pp. 103-129), y más allá de las desviaciones estructurales (Arroyo, 2013, pp. 24-29) que se han aceptado siempre, llega para quedarse.

En segundo lugar, se encuentra el propio derecho de acceso a la información pública. Esto es así toda vez que es reconocido como un derecho humano en el artículo $6^{0}$ de la Constitución Política de los Estados Unidos Mexicanos (en adelante CPEUM); además, en la misma exposición de motivos de la Ley General de Transparencia y Acceso a la Información Pública, el enfoque moral del derecho se asume como relevante.

En efecto, se ha observado que una de las justificaciones centrales del derecho al acceso a la información y de las políticas de transparencia, se encuentra en factores $y$ valores que van más allá de lo estrictamente jurídico y político, y tienen impacto sobre fenómenos morales como lo son la corrupción y la confianza (Cruz, p. 8).

Desde el momento mismo en que se consagra —en el artículo 6 de la CPEUM- como un derecho propio de toda persona y que, para ejercerlo, no se requiera argumentar justificación alguna, nos coloca en el umbral de un derecho fundamental. Efectivamente, al ser de alcance universal está en sincronía con la tesis que sostiene que los derechos fundamentales no son privativos únicamente de los ciudadanos, sino que deben ser garantizados a todos de manera irrestricta. Esto último es así por la simple razón de que, como lo explica Ernesto Garzón V., en voz de Cruz Revueltas:

Los derechos fundamentales son, precisamente, instrumentos de protección de los bienes básicos de la persona. Dicho de otra forma, son derechos que protegen aquellos bienes considerados como necesarios a la constitución del individuo, para que pueda actuar y responsabilizarse como agente moral (p. 8).

En tercer lugar, derivado del anterior argumento, se afirma que si todas las personas tienen el mismo valor, ello es así en virtud del principio de dignidad humana, entendido también éste como un valor moral el cual fija el umbral mínimo a partir del cual pueden diseñarse diversas regulaciones para la adjudicación y/o distribución de bienes en una sociedad (Garzón, 2006, p. 56).

Como cuarto punto, siguiendo la ruta argumentativa de Cruz Revueltas, si admitimos que el Estado constitucional y la democracia se fundan en valores morales fundamentales, entonces debemos aceptar, de la misma manera, que las instituciones políticas deben procurar obtener resultados moralmente aceptables (Cruz, 2015 , p.7). Dicho en otros términos, dado que el derecho es un fenómeno esencialmente político, i. e., tiene relaciones con la práctica política, algunas de estas relaciones son directas, mientras que otras se dan a través de la moral (Nino, 2014, p. 15).

Por último, si admitimos que los procesos y ejercicios políticos cotidianos deben estar sujetos a la discusión y escrutinio moral, entonces de igual manera debemos aceptar que esa discusión y ese escrutinio moral son condiciones imposibles de satisfacer sin el derecho de acceso a la información pública y las políticas de transparencia.

Son muchos los fenómenos que han abonado al fortalecimiento del derecho de acceso a la información pública. La consolidación de la democracia constitucional es uno de ellos. En ésta se exige cada vez mayor participación ciudadana en la toma de decisiones públicas, y ya no sólo se agota en la emisión del voto, sino que además requiere mayores mecanismos de participación ciudadana y social en todos los procesos del accionar gubernamental.

Por otra parte, el acelerado desarrollo en tecnología informática y la accesibilidad cada vez mayor que permite a más personas su utilización, han generado una conciencia clara de la importancia de la información para la toma de decisiones y para el control y vigilancia del quehacer público. Acciones que finalmente propenden por mejorar la calidad de vida de la población.

El derecho de acceso a la información pública y la transparencia como política pública, es uno de los componentes esenciales de la democracia en todos sus niveles. La democracia constitucional 
requiere una sociedad más participativa, y que dicha participación sea eficaz. Para ello, el acceso a la información es una herramienta fundamental.

El nuevo paradigma de democracia constitucional exige también una transformación en el ser y actuar de la administración pública. Se debe abandonar, en donde no se haya logrado, el modelo burocrático, rígido y legalista incapaz de atender las necesidades de una comunidad, garantizando los derechos humanos. Es la época de la gobernanza, entendida como aquella administración pública sensible y dinámica que atienda a las necesidades de la comunidad. Sensible para entender las nuevas exigencias y dinámica para modificar sus procesos en aras de transformar sus procedimientos para lograr sus objetivos. En ello la información oportuna es esencial. En este sentido, dentro de los múltiples contextos en los que se ha aplicado el concepto de gobernanza, resulta especialmente ilustrativo aquel que ha venido asociándose con lo relativo a la organización y funcionamiento de la administración pública y todas aquellas entidades que prestan los servicios de esa naturaleza. Se trata, como lo señala Francisco L. Laporta, de una idea de gobernanza que ha estado en sincronía con la tendencia contemporánea de reforma del sector público. Las características de esta corriente reformadora se pueden resumir así: primero, la práctica de introducir en el sector público aquellos principios de organización y management pertenecientes al sector privado, que giran en torno a las ideas económicas de eficiencia y programación por objetivos. Segundo, una oleada de privatizaciones de empresas y organismos del sector público. Tercero, la tendencia hacia aquello que se le ha denominado 'agencificación', es decir, el establecimiento de agencias autónomas o semiautónomas responsables del control y administración de ciertos sectores. Cuarto, la insistencia en la idea de competitividad, de tal forma que la competencia se traduzca en una especie de estímulo con el objetivo de incrementar la eficiencia en la prestación de servicios. Quinto y último rasgo distintivo, la idea cada vez más fuerte de descentralización, bajo el argumento de que los servicios y los policies que surgen de un tejido descentralizado tienden siempre a resultar más eficientes a diferencia de aquellos que emanan de agencias centrales o de una estructura muy centralizada (Laporta, 2014, pp. 48-49).
Finalmente, es en ejercicio del derecho a la información y la transparencia, en donde se encuentran las herramientas más eficientes para el combate a la corrupción, además de muchas otras utilidades que ofrece. En la consolidación de éstas se logrará abatir los índices de corrupción y con ello, fortalecer el ejercicio de los derechos humanos con la consecuente mejora en la calidad de vida y garantía de la dignidad de las personas como principio esencial. Esto exigió desde el principio la configuración de un sujeto autónomo no sólo desde el punto de vista moral, sino también desde el punto de vista político; en el sentido, más o menos como la describe A. Cortina: autonomía como aquella que capacita a los sujetos para ser reconocido como persona, sujeto de derechos humanos (2008, p. 140).

La prerrogativa de la población de acceder a la información pública es un nuevo control sobre el ejercicio del poder. Un elemento que no se desprende de los teóricos tradicionales de la democracia. Una nueva herramienta que fortalece a la población, el de someter a escrutinio todo el hacer público.

El DAIP es la prerrogativa que toda persona tiene de acceder y solicitar información pública. Derecho humano que como se ha dicho se contempla en la norma referencial del país. Por su parte, la transparencia es la política pública por la cual los sujetos obligados establecen los instrumentos, mecanismos o acciones para publicitar el manejo de los recursos públicos y todo su actuar.

El artículo 4 de la Carta Democrática Interamericana del 11 de septiembre de 2001 establece: "Son componentes fundamentales del ejercicio de la democracia la transparencia de las actividades gubernamentales, la probidad, la responsabilidad de los gobiernos en la gestión pública, el respeto por los derechos sociales y la libertad de expresión y de prensa."

En el informe acerca de la situación de los derechos humanos en Venezuela, elaborado por la CIDH y denominado "Institucionalidad democrática, Estado de derecho y derechos humanos en Venezuela", de diciembre de 2017, en los párrafos 333 y 334 hace hincapié en garantizar este derecho para el combate a la corrupción: 
333. Lo anterior evidencia, tal y como se constata a lo largo de este informe, que existe una política de secreto y control de información sobre asuntos públicos, que tiene graves consecuencias para la exigencia y promoción de otros derechos humanos en muy diversos ámbitos. La información esencial sobre el funcionamiento del Estado y las políticas públicas que debe ser publicada de manera proactiva por las autoridades, tales como datos sobre producción anual de alimentos, tasas de mortalidad materna e infantil, los índices de homicidios, entre otros, es sujeta a reserva sin base legal ni mecanismos eficaces de reclamo.

334. En vista de ello, la CIDH y su Relatoría Especial reiteran su recomendación al Estado de adoptar legislación en materia de acceso a la información pública, de conformidad con los estándares interamericanos, con la finalidad de otorgar a todas las personas las herramientas para realizar un efectivo monitoreo del funcionamiento estatal, la gestión pública y el control de la corrupción, esenciales en el proceso democrático. Asimismo, la CIDH y su Relatoría Especial hacen un llamado a las autoridades judiciales a que garanticen este derecho $\mathrm{y}$ en todo momento orienten sus fallos de conformidad con las normas internacionales que rigen la materia.

Es obligación del Estado constitucional de derecho poner a disposición la información que se genera y posee, generada en el ejercicio del actuar público, a fin de crear certeza y lograr la legitimidad que exige todo modelo democrático. A la vez, establecer los mecanismos de comunicación y accesibilidad que hagan oportuna y útil la información. De ello, finalmente vendrá la fiscalización y rendición de cuentas que acoten los espacios de la corrupción.

Teóricamente está resuelto que el poder es público (o político), y que emana del pueblo y debe de ejercerse en su beneficio. Sostenerlo en la práctica resulta más complejo. De ahí la insistencia en que uno de los elementos esenciales que garanticen esa "publicidad" es justamente generar los mecanismos que permitan a la población acceder a toda la información que dentro del ejercicio público se genera. El Estado de derecho como tal, debe de garantizar que todos sus actos no solo sean legales, sino además públicos. Para ello existe la prerrogativa de acceder a dicha información, el DAIP. Pero no solamente se debe otorgar el derecho, sino además, el Estado de manera activa tiene que generar un política pública de cara a la sociedad. No es tarea de un solo poder (o función), es la ruta a seguir tanto por el ejecutivo, como por el legislativo y el judicial. En este sentido, y en cuanto a el último de ellos, no es gratuita la reflexión de Betanzo Torres al sostener que "El grado de desarrollo de la transparencia repensado en los últimos trescientos años hacia la modernidad- nos coloca ante un punto de consenso. La transparencia es parte del oficio de los Jueces" (2014, p. 17).

\section{Como sostiene Ernesto Garzón}

(...) nada más peligroso para la existencia del Estado de derecho que la reducción de la publicidad de las medidas gubernamentales, sea dificultado el acceso a la información, sea mediante la práctica de la sanción de medidas secretas o de conocimiento reservado a un grupo de iniciados, tal como suele suceder en los regímenes totalitarios (1993, p. 77).

Bobbio por su parte advierte del peligro que corren las democracias si éstas no eliminan el "poder invisible", para ello "la obligación de la publicidad de los actos gubernamentales es importante, no sólo, como se dice, para permitir al ciudadano conocer las acciones de quien detenta el poder y en consecuencia de controlarlos, sino también porque la publicidad es en sí misma una forma de control, es un expediente que permite distinguir lo que es lícito de lo que es ilícito" (2018, p. 37).

Es sin duda una exigencia del Estado Constitucional, un ejercicio abierto y de cara a la sociedad de todo el quehacer público para lograr con ello sus fines, legitimar su función y lograr los fines del Estado otorgando una mejor calidad de vida de toda la población.

\section{CONCLUSIONES}

Cada vez es más común escuchar voces que reclaman Estados más abiertos y ciudadanías más participativas en la toma de decisiones respecto de lo público $\mathrm{y}$, consecuentemente, hemos estado atestiguando nuevos contornos en las expresiones también de lo público, de tal modo que los conceptos de viejo cuño $-\mathrm{y}$ la irradiación de su campo semántico- en ciertas 
condiciones no alcanzan a cubrir esos nuevos contornos, esas nuevas expresiones. Las nuevas realidades terminan re-moldeando las viejas conceptualizaciones e invierten la significación. Por ello, en estricto sentido, Victoria Camps (1986, p. 80) no deja de tener razón cuando advierte que, en cuanto al concepto de 'democracia', más allá de su denominación como autogobierno, que no es sino una manera obsoleta e irreal de definirla, ésta debería definirse como la transparencia de lo público. Y es que si, finalmente, en términos de H. Meloti (1972), los problemas de denominación suelen resolverse convencionalmente, y si el principio de publicidad -en clave de dinámica de transparencia- constituye el eje rector, el leit motiv de la operatividad estatal del siglo XXI de cara a una ciudadanía crítica y vigilante, entonces tendríamos que convenir sobre la necesidad de transitar a lo dicho por la filósofa moral: lo transparente como el componente esencial y definitorio de la idea de democracia del siglo XXI. Lo que está en juego en esta propuesta de entender la democracia, es precisamente la posibilidad de que el significado mismo, su núcleo semántico, obtenga su contenido a partir de lo transparente como rasgo distintivo y definitorio. La cúspide de esta propuesta se encuentra en la adopción, en los textos constitucionales del presente siglo, de esa nueva forma de entender la democracia, es decir, una sinonimia que refleje esos nuevos contornos en el ejercicio cotidiano de la vida institucional y estatal.

\section{BIBLIOGRAPHY}

- Arroyo G., J. M. (2013). Ética y derecho en democracia. Ciudad de México: Instituto de Investigaciones Jurisprudenciales y de Promoción y Difusión de la Ética Judicial (SCJN).

- Barberis, M. (2008). Ética para juristas. Madrid: Trotta.

- Betanzos T., E. O. (2014). La transparencia en el Código Modelo Iberoamericano de Ética Judicial. Ciudad de México. Instituto de Investigaciones Jurisprudenciales y de Promoción y Difusión de la Ética Judicial (SCJN).

- Bobbio, N. (1996). El futuro de la democracia Ciudad de México: Fondo de Cultura Económica.

- Camps, V. (1996). El malestar en la vida pública. Barcelona: Grijalbo.

- Carbonell, M., Cruz Parcero, J. A., y Vásquez, R. (Comps.). (2004). Derechos sociales y derechos de las minorías. Ciudad de México: Porrúa-UNAM.

- Cienfuegos, D. (Coord.). (2008). Estado, derecho y democracia en el momento actual. Contexto y crisis de las instituciones contemporáneas. Ciudad de México: FEJ.

- Corte Interamericana de Derechos Humanos. Opinión consultiva OC-9/87 del 6 de octubre de 1987.
- Cortina, A. (2008). Ética aplicada y democracia radical. Madrid: Técnos.

- Cruz R., J. A. (2015). Moral y transparencia. Fundamento e implicaciones morales de la transparencia. Ciudad de México: INAI.

- Dworkin, R. (2014). Justicia para erizos. Ciudad de México: FCE.

- Espinoza de los M., J. (2018). Las dimensiones del Estado Constitucional. Ciudad de México: Centro Iberoamericano de Investigaciones Jurídicas y Sociales.

- Ferrajoli, L. (2011). Principia iuris, I. Teoría del Derecho. Madrid: Trotta.

- Fioravanti, M. (2016). Los derechos fundamentales. Apuntes de historia de las constituciones. Madrid: Trotta.

- Garzón V., E. (2006). “¿Cuál es la relevancia moral del concepto de dignidad humana?". En: Cátedra Ernesto Garzón Valdés 2005. Ciudad de México: ITAM-Fontamara-UAMEscuela Libre de Derecho-INACIPE.

- Garzón V., E. (1993). Acerca de los conceptos de publicidad, opinión pública, opinión de la mayoría y sus relaciones recíprocas. Doxa. No. 14, 77-95.

- Laporta, F. J., (2014). Gobernanza y soft law: nuevos perfiles jurídicos de la sociedad internacional. Madrid: [Sin editorial].

- Mazzarese, T. (2011). Derecho y democracia 
constitucional. Una discusión sobre Principia Iuris de Luigi Ferrajoli. Lima: Ara editores.

- Mejía R., J. (2018). Diez cuestiones actuales sobre derechos humanos. Ciudad de México: Instituto de Estudios Constitucionales.

- Meloti, H. (1972). Revolución y sociedad. Ciudad de México: FCE.

- Miaille, M. (1985). El Estado del derecho. Ciudad de México: Universidad Autónoma de Puebla.

- Morales A., M. (2018). Aproximación a los estándares interamericanos sobre corrupción, institucionalidad democrática y derechos humanos. En: Tablante, Carlos et al. Ciudad de México: Instituto de Estudios Constitucionales.

- Nino, C. (2014). Derecho, moral y política. Una revisión de la teoría general del Derecho. Buenos Aires: Siglo XXI Editores.

- Organización de Estados Americanos (S. F. ). Carta Democrática Interamericana. Disponible en: https://www.oas.org/ charter/docs_es/resolucion1_es.htm

- Orozco H., J. J. (2007). "Comentario el concepto de Estado de Derecho". Diccionario Jurídico Mexicano. Ciudad de México: Porrúa.

- Prieto S., L. (s. f.). El constitucionalismo de los derechos. Ensayos de filosofía jurídica. Madrid: Trotta.

- Revenga S., M. (2019). Sobre el derecho constitucional y sus fundamentos. Segunda parte. Rechtsstaat y teoría de la constitución en el periodo de entre guerras. Derechos en acción, 13(13):330.

- Reyes H., F. (2012). “Corrupción: de los ángeles a los índices”. En: Cuadernos de Transparencia. Ciudad de México: Ifai.

- Vázquez, R. (2015). Derechos humanos. Una lectura liberal igualitaria. Ciudad de México: IIJ.

- Zagrebelsky, G. (2009). El derecho dúctil. Ley, derechos, justicia. Madrid: Trotta. 